\title{
Effects of Haze Experiments by Artificial Intervention on Atmospheric Mixing Layer Height (MLH) and Air Pollution in Pearl River Delta Region
}

\author{
Duan PENG ${ }^{\mathrm{a}, 1}$, Chang LIU ${ }^{\mathrm{b}}$, Meiling $\mathrm{CHEN}^{\mathrm{c}}$, Chunlin XU ${ }^{\mathrm{d}}$ and Minyan LIANG \\ ${ }^{a}$ Zhaoqing Meteorological Bureau of Guangdong Province, Zhaoqing 526060, \\ Guangdong, China \\ ${ }^{\mathrm{b}}$ Climate Center of Guangdong Province, Guangzhou 510080, Guangdong, China \\ ' Guangdong Emergency Early Warning Release Center, Guangzhou 510080, \\ Guangdong, China \\ d Sihui Meteorological Bureau of Guangdong Province, Sihui 526200, Guangdong, \\ China \\ e Jiangmen Meteorological Bureau of Guangdong Province, Jiangmen 529030, \\ Guangdong, China
}

\begin{abstract}
In this paper, the effects of 16 times of aircraft artificial intervention operations on atmospheric MLH and air pollution in Pearl River Delta Region were investigated. By analyzing the surface observation meteorological data collected hourly each day from 2015 to 2019 using the Nozaki Method and Statistical Analysis Method, the differences of MLH's daily variations on haze and non-haze days were studied. Then the variations of MLH, pollutant concentrations and visibility before and after artificial intervention were studied. And the variations in the concentration of fine particles were obtained by analyzing the depolarization ratio's vertical distribution detected by Guangzhou Polarized Micropulse Lidar System. Finally, the analysis of daily average air pollutant concentrations and thickness of atmospheric mixing layer, together with the analysis of MLH, surface ventilation and the corresponding pollutant concentration sequence 18 hours post-experiment can lead to effects of MLH on air pollution. The results showed that (1) MLH varies daily significantly; (2) The atmospheric MLH, air pollutant concentration and visibility vary significantly after aircraft artificial precipitation intervention: (a) the MLH and surface ventilation increase during the first three hours of rainfall; (b) the visibility increases significantly; (c) the concentrations of $\mathrm{PM}_{2.5}$ and $\mathrm{PM}_{10}$ decrease while the concentrations of coarse and modal particles show a significant trend of decrease; (d) the subsequent dilution effect on $\mathrm{PM}_{2.5}$ and $\mathrm{PM}_{10}$ also show out in a clear way, especially on $\mathrm{PM}_{10}$. The daily average concentrations of $\mathrm{PM}_{2.5}$ and $\mathrm{PM}_{10}$ are positively correlated with the daily average MLH in the region and the correlation coefficients are -0.71 and -0.63 respectively. After haze experiments by artificial intervention, $\mathrm{PM}_{2.5}, \mathrm{PM}_{10}, \mathrm{SO}_{2}, \mathrm{NO}_{2}, \mathrm{CO}$ and $\mathrm{AQI}$ indexes were negatively correlated with MLH and surface ventilation while positively correlated with $\mathrm{O}_{3}$. The research results show its value in the aspects of the atmospheric environmental quality assessment and pollutant diffusion capacity improvement in the region. It also helps in future data demonstration tests for the effects of haze
\end{abstract}

${ }^{1}$ Corresponding Author, Duan PENG, Zhaoqing Meteorological Bureau of Guangdong Province, Zhaoqing 526060, Guangdong, China; Email: 1047539010@qq.com. 
experiments by artificial intervention on atmospheric turbulence and air pollution elimination. And it provides scientific decision-making basis for future relevant measures for the quality of urban atmospheric environment improvement.

Keywords. Haze experiments by artificial intervention, atmospheric MLH, air pollution, effects, Pearl River Delta Region

\section{Introduction}

The provention and control of air pollution has been the main focus in recent years. Previous researches have shown that proper artificial invervention on weather can be applied to clean air and reduce the impact of haze [1-3]. Gao [4] studied the feasibility of artificial precipitation and haze elimination in the Pearl River Delta Region and concluded that in favorable weather, the precipitation can be increased and the wet deposition process can be enhanced by artificial precipitation, thus the air quality is improved and the severity of haze is reduced. At present, artificial precipitation technology and the effect test of it in China are relatively mature [5-7]. Gao et al. [8] have establised a Guangdong Spring Aircraft Artificial Precipitation Conceptual Model. Therefore, except for the enhancement of rainfall during the artificial precipitation, does it effect on MLH and pollutant concentration near the ground? During the variation of mix layer, the height of it represents the maximum height that pollutants can reach in the vertical direction due to the dilution and diffusion of turbulence and convection activities. The observation and calculation methods of atmospheric MLH, together with the corresponding effects on air pollution have been researched for many times from all over the world. Cao et al. [9] compared and analyzed the variation characteristics of daily maximum mixed layer thickness and its effects on air pollution in Xi'an by using statistical methods, and concluded that the daily maximum mixed layer thickness has significant negative correlation with air pollutant concentration. Zhou et al. [10] calculated the atmospheric MLH in Sichuan Basin using National Standard Method, Nozaki Method and Joint Frequency Method and concluded that the MLH is correlated negatively with the overall AQI. Li et al. [11] observed the MLH in the most polluted February of 2014 in Beijing-Tianjin-Hebei Region using ceilometer, from which they summarized that the bad atmospheric vertical diffusion condition was the main reason for the long-time high concentration pollution near the ground in Shijiazhuang. Liao et al. [12] proposed five methods for the MLH determination: National Standard Method, Dry Adiabatic Method (DAM), Nozaki Method, Joint Frequency Method-Nozaki Method, Actual Measurement Method. Yu et al. [13] calculted the MLH on haze days in Ningbo using Nozaki Method and discovered that the MLH has obvious characteristics of seasonal and daily variations. You Huanling [14] analyzed the temporal variation characteristics of the average maximum mixed layer thickness in Beijing using Successive Approximation Method. By applying Dry Adiabatic Method, Liao [15] estimated and calculated the maximum MLH which represents the atmospheric mixing class in the vertical direction, and probed into the correlation between the maximum MLH and the pollutant concentration observed on the ground. However, there is still no such research about the effects of artificial aircraft precipitation intervention on atmospheric MLH in Pearl River Delta Region.

In this paper, based on the surface observation meteorological data collected from 2015 to 2019 hourly and daily in the region, the difference of atmospheric MLH's daily variations between haze and non-haze days by Nozaki Method and Statistical Analysis 
Method was analyzed. Based on the surface observation meteorological data collected from 2015 to 2019 hourly and daily in the region, the difference of atmospheric MLH's daily variations between haze and non-haze days by Nozaki Method and Statistical Analysis Method was analyzed firstly. Then variations of MLH, pollutant concentration and visibility before and after artificial intervention were studied. And the variations in the concentration of fine particles were obtained by analyzing the depolarization ratio's vertical distribution detected by Guangzhou Polarized Micropulse Lidar System. Afterwards, the paper analyzed the daily average air pollutant concentrations and thickness of atmospheric mixing layer, and compared the $\mathrm{PM}_{2.5}, \mathrm{PM}_{10}, \mathrm{SO}_{2}, \mathrm{NO}_{2}, \mathrm{CO}, \mathrm{O}_{3}$ and $\mathrm{AQI}$ indexes after 16 times of artificial aircraft precipitation intervention operations in 18 hours post-experiment observations with the corresponding average daily air pollutant concentrations and surface ventilation sequence during 2017-2019 in the region. Finally, the effects of MLH variations after precipitation interventions on air pollution were carried out. The research results show its value in the aspects of the atmospheric environmental quality assessment and pollutant diffusion capacity improvement in the region. It helps in future data demonstration tests for the effects of haze experiments by artificial intervention on atmospheric turbulence and air pollution elimination. The research also contributes to improving the understanding and practical efficiency of artificial precipitation intervention and provides scientific decision-making basis for future relevant measures for the quality of urban atmospheric environment improvement.

\section{Materials and Methods}

\subsection{Confirmation of $M L H$}

Generally, if local radiosonde data are available, DAM can be used for MLH determination [16]. In this method, the temperture profile on Emagram (08h) is generated based on the sounding data of daily air temperature at local time 08:00. The surface temperature at 14:00 on that day is taken as the dry adiabatic curve $\left(r_{d}\right)$. And the vertical distance bewteen the intersection of the profile and curve (point A) and the underlying surface is called daily average maximum MLH (figure 1).

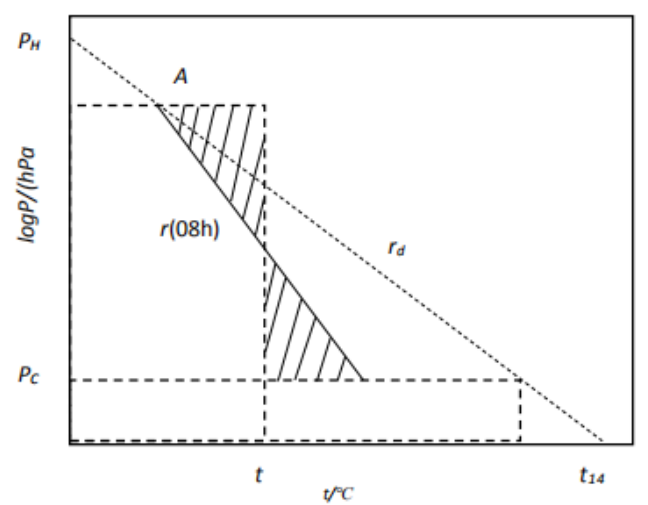

Figure 1. Determination of MLH by DAM. 


\subsection{Calculation of $M L H$}

For stations without radiosonde data, MLH can be estimated by surface meteorological parameters. Nozaki held the opinion that the atmospheric mixing layer was affected by thermal and mechanical turbulence. And there was interaction and feedback between the air motion in the upper boundary layer and the surface meteorological parameters. Liao Guolian and Shi Baozhong calculted the MLH by surface meteorological parameters based on Nozaki Method and proposed the following equation:

$$
\mathrm{L}=\frac{121}{6}(6-\mathrm{p})(\mathrm{T}-\mathrm{Td})+\frac{0.169(\mathrm{Uz}+0.257)}{12 \mathrm{fln}\left(\frac{\mathrm{z}}{\mathrm{z} 0}\right)}
$$

where $\mathrm{L}$ is the average $\mathrm{MLH}(\mathrm{m})$; T-Td is the dew point depression $\left({ }^{\circ} \mathrm{C}\right)$; $\mathrm{P}$ is the value of Pasquill stability classes (table 1); $\mathrm{Uz}$ is the average wind speed observed at altitude $\mathrm{Z}\left(\mathrm{m} \cdot \mathrm{s}^{-1}\right) ; \mathrm{Z} 0$ is the surface roughness $(\mathrm{Z} 0$ is about $1.0 \mathrm{~m}$ calculted based on the data the authors observed in the region); $f$ is the geostrophic parameter $\left(\mathrm{s}^{-1}, \mathrm{f}=2 \Omega \sin \varphi\right.$ : $\varphi$-the geographic latitude and $\Omega$-the angular speed of Earth's rotation).

The research by Shi Baozhong [16] showed that the monthly average MLHs calculted based on DAM and Nozaki Method within a similar changing trend. And the two results were significant correlated with each other, with the MLH by Nozaki Method being relatively low. Liao Guolian et al. [12] considered that the atmospheric MLH calculated by Nozaki Method has a wide application value in areas without high altitude meteorological observation. Therefore MLH calculation for the areas like Conghua, Gaoyao, Qingyuan stations without radiosonde data was reasonable.

Table 1. $p$ values of different atmospheric stability.

\begin{tabular}{ll}
\hline Atmospheric stability & $\mathbf{p}$ \\
\hline Highly instability & 1 \\
Highly instability-instability & 1.5 \\
Instability & 2 \\
Instability-Weak instability & 2.5 \\
Weak instability & 3 \\
Weak instability-Neutral & 3.5 \\
Neutral & 4 \\
Weak stability & 5 \\
Stability & 6 \\
\hline
\end{tabular}

\subsection{Ventilation Calculation}

$\mathrm{Xu}$ Dahai [17] defined the calculation of ventilation which is a parameter characterizing the motion state of the atmospheric boundary layer according to the following equation:

$$
\mathrm{VE}=\mathrm{U} \times \mathrm{H}=\int H U(Z) \mathrm{dz} \approx 1.6 \mathrm{u}(\mathrm{H}-26)
$$

where VE is the ventilation; $\mathrm{u}$ is average wind speed $\left(\mathrm{m} \mathrm{s}^{-1}\right) ; \mathrm{H}$ is the MLH $(\mathrm{m})$, calculated based on the suggested method in Technical Methods for Setting Local Air Pollutant Emission Standards (GB/T 13201 91). 


\subsection{Air Pollutant Mass Concentration Data}

The mass concentration data of air pollutants $\mathrm{PM}_{2.5}, \mathrm{PM}_{10}, \mathrm{SO}_{2}, \mathrm{NO}_{2}, \mathrm{CO}, \mathrm{O}_{3}, \mathrm{AQI}$ came out of the hourly concentration data colllected by 56 national ambient air quality stations in Pearl River Delta Region provided by Department of Ecology and Environment of Guangdong Province, Environmental and Meteorological Organization Service (EMOS) in South China Region.

\section{Characteristic of MLH Daily Variation on Haze and Non-haze Days}

Hourly surface observation meteorological data of recent five years (January-April from 2015-2019) in the region (taking Conghua Station as example) has been chosen in the paper. The daily average MLH was calculated by Nozaki Method. And the difference of MLH daily variation during haze and non-haze days in the region was analysed.

The hourly average MLH was calculted from the data of 23 haze days (Daily average visibility less than $3 \mathrm{~km}$ is defined as a haze day) and 112 non-haze days (Daily average visibility more than $10 \mathrm{~km}$ is defined as a non-haze day except for raining days) of the same time period in same station has been chosen in the paper. The diurnal variation curve of MLH on haze days and non-haze days were obtained (figure 2).

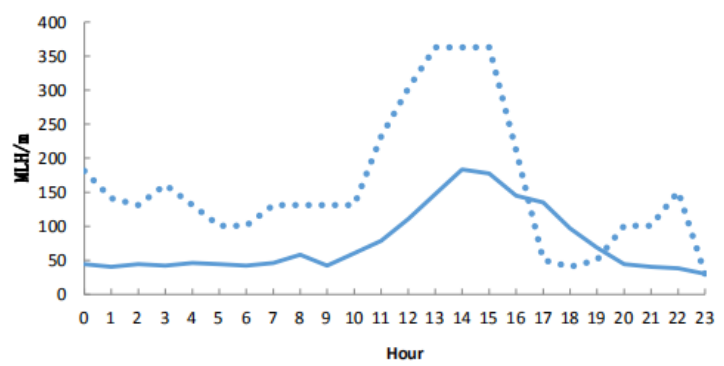

Figure 2. Diurnal variation of MLH on haze (Solid line) and non-haze (dotted line) days in the Pearl River Delta Region.

The correlation coefficient of the diurnal variation between MLH on haze days and non-haze days was 0.70 . This result showed that the MLH was affected by temperature, humidity and wind despite of the day is haze-free or not, and there is an obvious diurnal variation. Figure 2 clearly showed the diurnal variation trend of mean MLH in haze days and non-haze days was similar. The variation was smooth from night to 10:00, and then increased gradually from 11:00, with a obvious peak value from 13:00 to 15:00. MLH in non-haze days was comparatively higher than that in haze days and was averagely about one time higher.

\section{Variations of MLH, Pollutant Concentration and Visibility before and after Artificial Intervention}

There was aircraft artificial precipitation intervention for 16 times from 2017 to 2019 in the region, and the flight routes has been summarized as shown in figure 3 . The 
maximum working height of the aircraft artificial operation on April 11, 2019 was 2800-3100 m, with a flight velocity of 180-310 $\mathrm{kmh}^{-1}$. The flight path of it was Yangjiang-Yunfu-Zhaoqing-Foshan-Guangzhou, starting from 12:40 and ending at 14:44. According to upper-air chart, the wind was southwest by west while the working height was about $3000 \mathrm{~m}$. Therefore, Qingyuan and northern Guangzhou were under the dominant wind and affected areas while Gaoyao and Dongguan in eastern Guangzhou were not under the dominant wind but non-affected areas. The variations of MLH, surface ventilation, rainfall and particulate matter concentration in the affected and non-affected areas were observed and calculated.

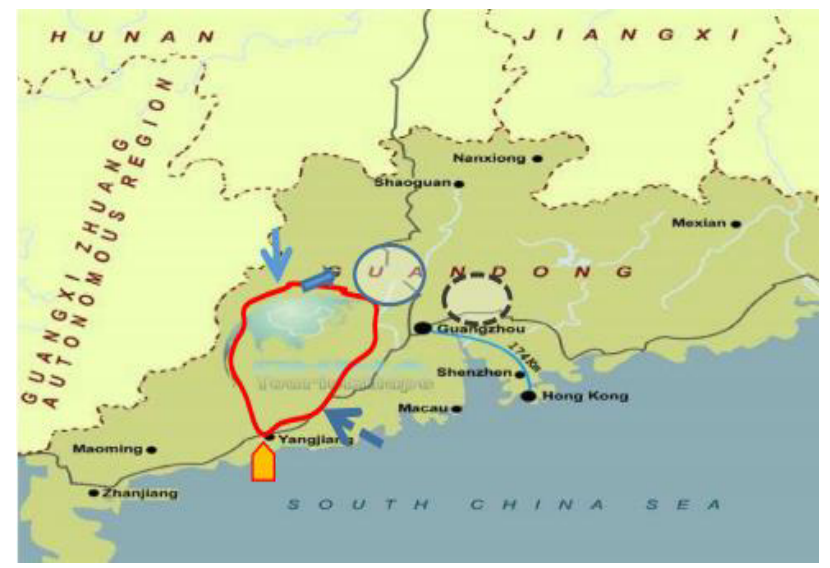

Figure 3. The flight path map of the aircraft artificial precipitation intervention on April 11, 2019 (the solid arrow is the flight path of precipitation; the dashed arrow is the flight path of non-precipitation; $\square$ is the wind direction at the height of the operation; the solid coil is the operation effect area, and the dotted coil is the non-operation effect area).

\subsection{Variations of MLH before and After Intervention}

The data from affected areas-Conghua (figure 4) and Qingyuan (figure 5) were compared and analyzed before and after artificial intervention for the effects of it on MLH.

As shown in figure 4, Conghua located at the downstream of Gaoyao, and the MLH and surface ventilation were with a bimodal structure. One of the peak value appeared at 14:00, which was affected by daily variation and another peak at 19:00, valley at 16:00. A microprecipitation occured at 15:00 with rainfall amount of $0.1 \mathrm{~mm}$, while a light rain of 1.0-4.2 mm occured at 19-20:00. The results showed that the MLH and surface ventilation rate increased 3 hours before the rainfall (17:00, 18:00 and 19:00) after the intervention. The distance between Qingyuan and the operation point was $125 \mathrm{~km}$. And the microprecipitation occured one hour later as shown in figure 5. The MLH and surface ventilation increased continuously three hours after the operation (16:00, 17:00 and 18:00). And a light rain of 0.8-8.7mm occured at 19:00-20:00. 


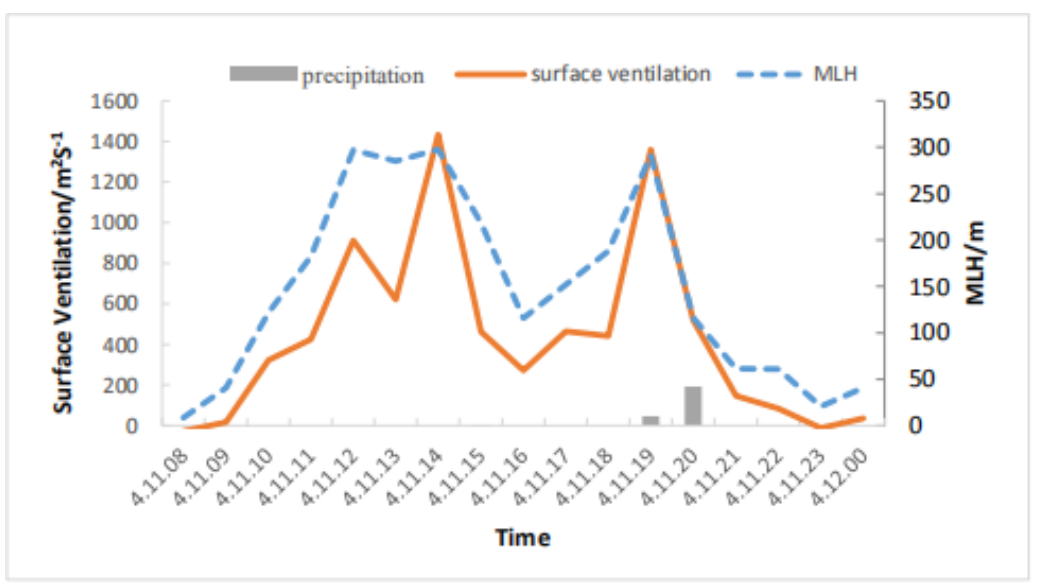

Figure 4. Time sequent diagram of MLH, surface ventilation and precipitation of Conghua Station (representative station of operation affected area) before and after intervention operation.

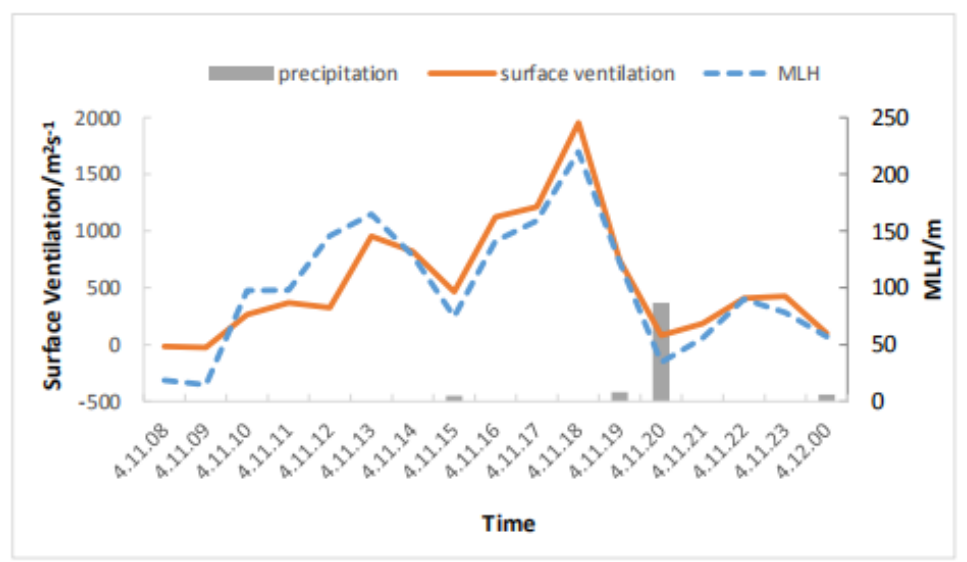

Figure 5. Time sequent diagram of MLH, surface ventilation and precipitation of Qingyuan Station (representative station of operation affected area) before and after intervention operation.

For a more detailed effects observation of artificial intervention, the MLHs and surface ventilation variations in non-affected and affected areas were compared. Dongguan was $170 \mathrm{~km}$ far from the operation point, which was within the non-affected area but not under the dominant wind. The MLHs, surface ventilations and precipitation rates of Dongguan and Gaoyao station from 08:00 on April 11 to 00:00 on April 12 were shown in figures 6 and 7 respectively.

As shown in the two figures, the MLHs, surface ventilations from Dongguan and Gaoyao station started to increase suddenly, to a peak value during 14:00-15:00 continuously and started to fall down at 16:00-17:00, so did the surface ventilations. They all showed in a unimodal distribution way, which was consistent with the daily variation trend of the average MLH.

Artificial precipitation not only promoted cloud convection, but also enhanced the movement of atmospheric turbulence near the surface layer comparing the variations of MLHs in affected and non-affected areas. The MLH and surface ventilation both had an increasing trend three hours before rainfall. When it started to rain, the atmospheric 
turbulence near the surface layer was occupied and replaced by the downdraft, and the MLH decreased rapidly.

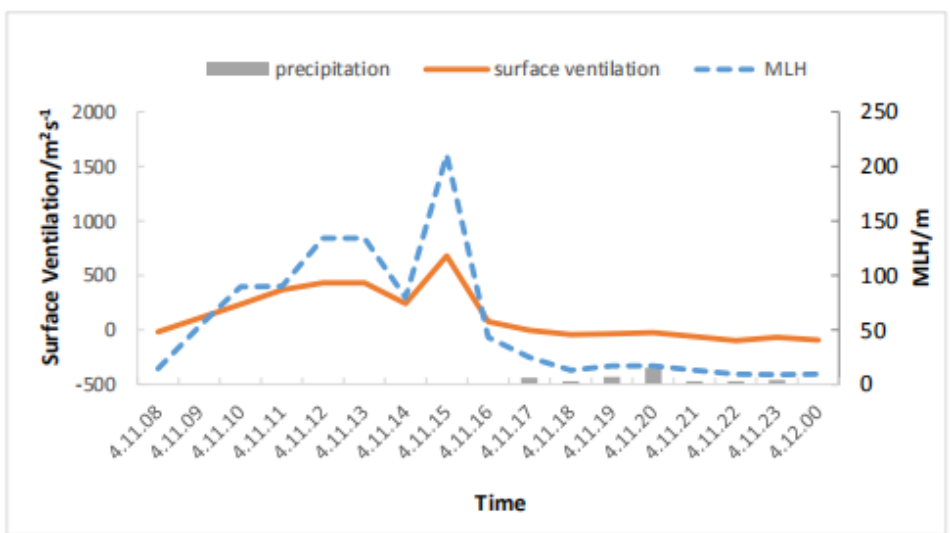

Figure 6. Time sequent diagram of MLH, surface ventilation and precipitation of Dongguan Station (representative station of operation non-affected area) before and after intervention operation.

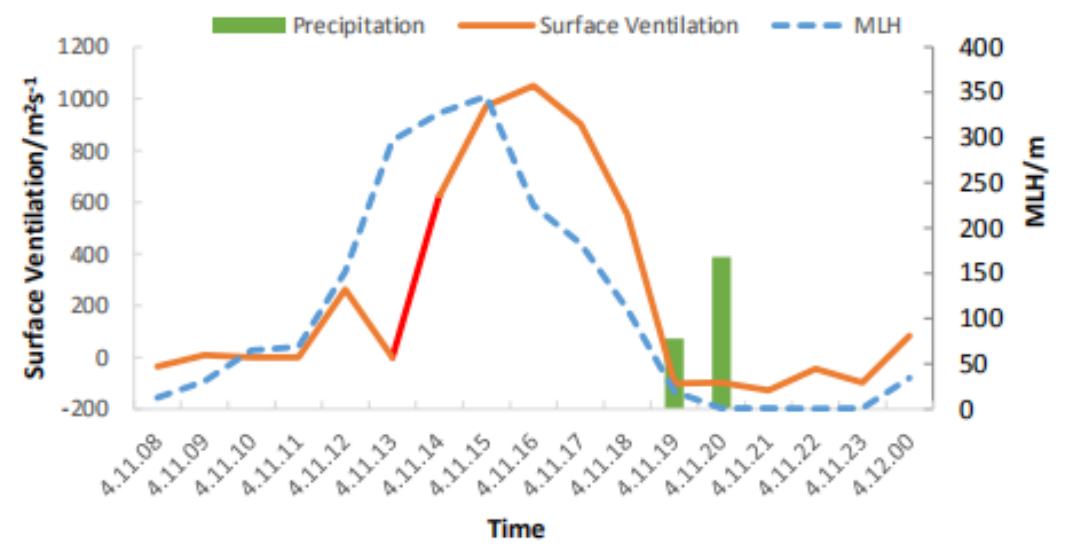

Figure 7. Time sequent diagram of MLH, surface ventilation and precipitation of Gaoyao Station (representative station of operation non-affected area) before and after intervention operation.

\subsection{Analysis of Data Detected By Polarized Micropulse Lidar before and after Intervention}

Polarized Micropulse Lidar is an effective tool to analyze the particle morphology by detecting the shape of non-spherical particles' depolarization characteristics of backscattered light. And it was used widely in research on atmospheric aerosols, dusts and clouds, etc. In the research by Welton et al. [18-19], lidar was used to detect the vertical distributions of aerosol optical properties in Indian Ocean Experiment (INDOEX). And lidar and wind profile were used by Cohn et al. [20] in their research on boundary layer height detection. He Qianshan et al. [21] used for the vertical distribution of atmospheric mixing layer and aerosol in Beijing. 
From the vertical distribution of depolarization ratio detected by Guangzhou Polarized Micropulse Lidar System on April 11, when artificial intervention was carried out, the accumulation mode particle number concentration below $400 \mathrm{~km}$ was very small and stable, while the coarse particle number concentration over $800 \mathrm{~km}$ was big, the peak value more than 0.15 and decreased significantly during 13:00-17:00. The time period was two hours after intervention and it indicated that the particle number concentration of coarse particles showed a decreasing trend after intervention (figure 8).

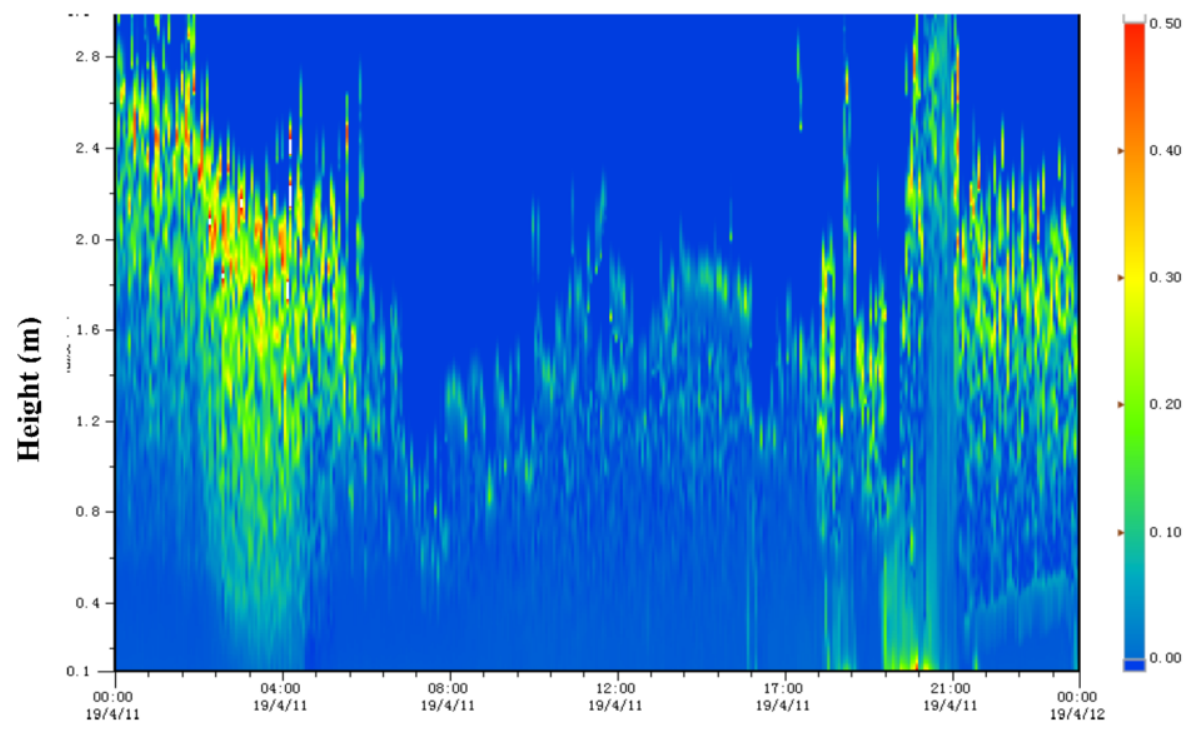

Figure 8. The vertical distribution of depolarization ratio detected by Guangzhou Polarized Micropulse Lidar System before and after intervention operation.

\subsection{Effects of Artificial Intervention on Air Pollution}

\subsubsection{Variations of Pollutant Concentration}

Precipitation and Visibility. Comparing and analysing the 16 operations, the variations of pollutant concentration, precipitation and visibility as shown in table 2 , there were obvious precipitation for 8 times, visibility increased for 8 times, fine particle concentration decreased obviously for 9 times, and the fine particle concentration decreased without no obvious precipitation for 4 times. From the variation of fine particle concentrations before and after the intervention, the fine particle concentration decreased for 13 times during the first day after the intervention, and the probability of the decrease was $86.7 \%$.

\subsubsection{Variations of the Concentrations of Pollutants}

Four traditional operations were chosen from the 16 interventions, and the variations of the concentrations of the following pollutants: $\mathrm{PM}_{2.5}, \mathrm{PM}_{10}, \mathrm{SO}_{2}, \mathrm{NO}_{2}, \mathrm{CO}, \mathrm{O}_{3}, \mathrm{AQI}$ were analyzed as shown in figure 9. From the figure, the concentrations of $\mathrm{PM}_{2.5}, \mathrm{PM}_{10}$, AQI showed a decreasing trend, $\mathrm{SO}_{2}$ a light decreasing trend, $\mathrm{NO}_{2}, \mathrm{CO}, \mathrm{O}_{3}$ a smooth variation. Therefore, the artificial intervention has significant effects on fine particles like $\mathrm{PM}_{2.5}, \mathrm{PM}_{10}$, and no significant effects on $\mathrm{SO}_{2}, \mathrm{NO}_{2}, \mathrm{CO}$ and $\mathrm{O}_{3}$. 

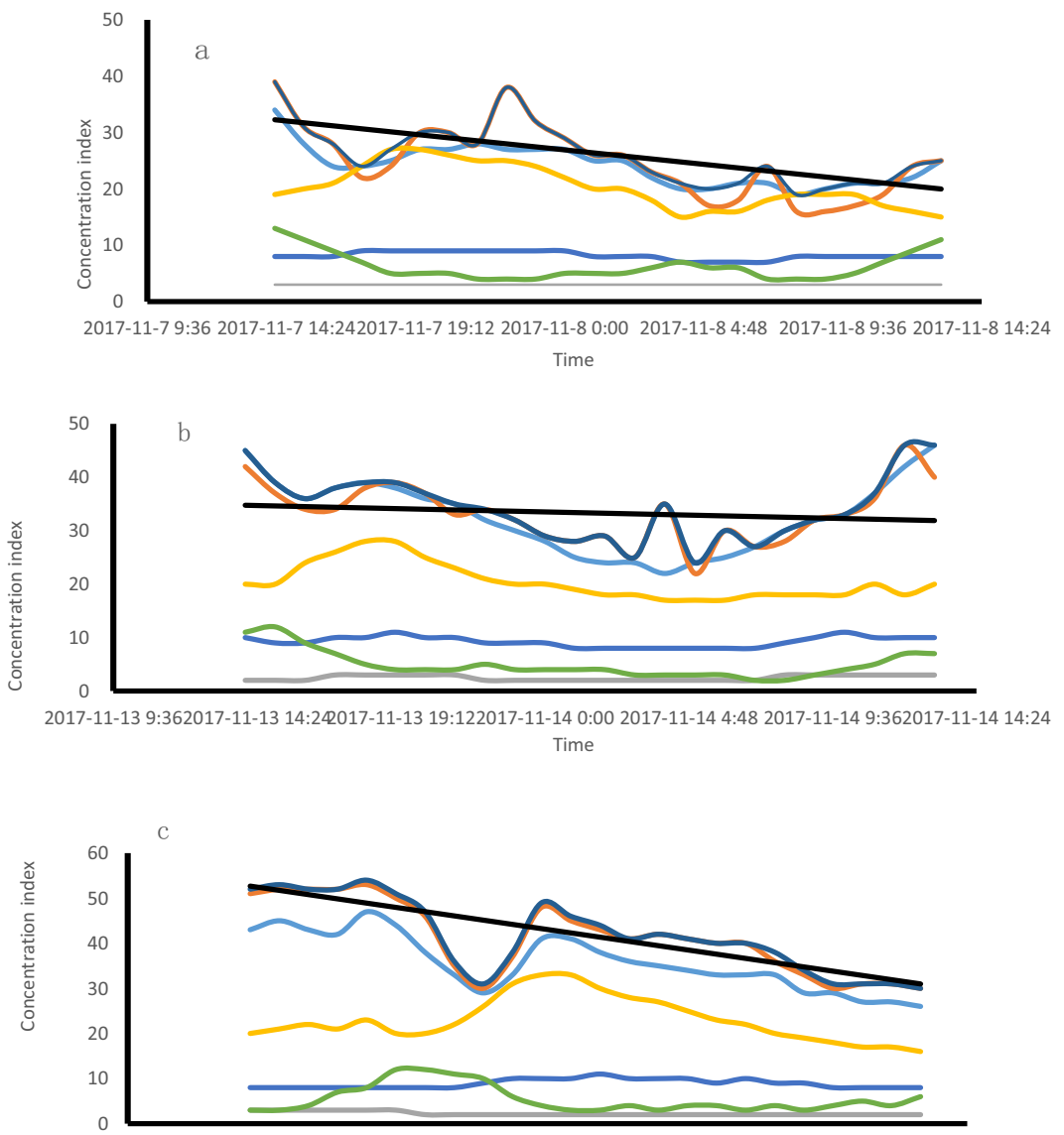

2019-3-29 4:48 2019-3-29 9:36 2019-3-29 14:242019-3-29 19:12 2019-3-30 0:00 2019-3-30 4:48 2019-3-30 9:36 Time

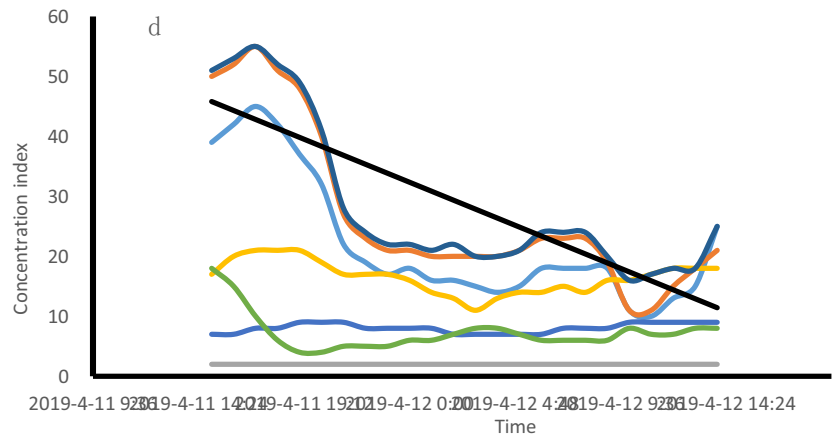

$$
\begin{array}{ll}
-\mathrm{PM} 2.5 & -\mathrm{PM} 10 \\
\text { so2 } & \text { NO2 } \\
\mathrm{co} & -\mathrm{O} 3 \\
\mathrm{AQl} & - \text { Linear Trend (AQD) }
\end{array}
$$

Figure 9. Variations of pollutant concentrations after four artificial intervention operations on: (a) November 7, 2017, (b) November 13 2017, (c) March 29, 2019, (d) April 11, 2019. 
Table 2. The variations of pollutant concentration, precipitation and visibility in 24 hours after artificial intervention.

\begin{tabular}{lllllll}
\hline \multicolumn{2}{l}{ The variations } & & PM $_{\mathbf{2 . 5}}$ & $\mathbf{P M}_{\mathbf{1 0}}$ & Precipitation (mm) & Visibility \\
\hline Date & Start time & End time & & Increase \\
\hline $2017 / 11 / 7$ & $13: 23: 00$ & $15: 58: 00$ & down & down & 0.1 & No Change \\
$2017 / 11 / 8$ & $12: 47: 00$ & $15: 20: 00$ & up & up & 0 & Increase \\
$2017 / 11 / 13$ & $12: 58: 00$ & $16: 06: 00$ & down & down & 13 & No Change \\
$2017 / 11 / 14$ & $12: 33: 00$ & $15: 03: 00$ & up & up & 0.1 & Increase \\
$2017 / 11 / 18$ & $12: 15: 00$ & $15: 00: 00$ & down & down & 0 & Increase \\
$2018 / 4 / 5$ & $11: 08: 00$ & $13: 10: 00$ & down & down & 0 & No Change \\
$2018 / 4 / 6$ & $09: 26: 00$ & $12: 05: 00$ & down & down & 6 & No Change \\
$2018 / 4 / 14$ & $09: 53: 00$ & $10: 34: 00$ & down & down & 5 & Increase \\
$2018 / 4 / 15$ & $14: 06: 00$ & $16: 47: 00$ & down & down & 2 & Increase \\
$2018 / 4 / 21$ & $09: 48: 00$ & $11: 55: 00$ & down & down & 0 & Increase \\
$2018 / 4 / 23$ & $14: 48: 00$ & $15: 13: 00$ & down & down & 2 & Increase \\
$2018 / 4 / 27$ & $12: 00: 00$ & $14: 30: 00$ & down & down & 0.1 & Increase \\
$2018 / 5 / 7$ & $14: 30: 00$ & $15: 00: 00$ & down & down & 16 & Increase \\
$2019 / 3 / 29$ & $09: 15: 00$ & $11: 01: 00$ & down & down & 2 & Increase \\
\hline
\end{tabular}

\subsubsection{Subsequent Effects on Air Pollution}

To study the subsequent effects of artificial intervention on air pollution, the correlation coefficients of the pollutant concentrations between the second and the first day after each operation for 15 times (16 times in total, but two of which were operated in the same day of April 23, so they were counted as once) interventions were analyzed as shown in table 3 . From the table, it can be seen that the biggest correlation coefficients were for $\mathrm{PM}_{10}$ and $\mathrm{PM}_{2.5}$, each of which was 0.84 and 0.9 respectively and they both went through the significance test of 0.001 . The probability of correlation coefficients bigger than 0.5 for $\mathrm{PM}_{10}$ (the significance test of 0.02 ) was $73.3 \%$ while the probability for $\mathrm{PM}_{2.5}$ was $66.7 \%$ and the AQI (Air Quality Index) was $60 \%$. The correlation coefficients for $\mathrm{PM}_{10}$ and $\mathrm{PM}_{2.5}$ were 0.58 and 0.56 (the significance test of 0.01 ) on average. AQI was 0.52 (the significance test of 0.02 ) on average. And the correlation coefficients for $\mathrm{O}_{3}$ and $\mathrm{NO}_{2}$ were 0.68 and 0.61 (the significance test of 0.01 ) on average. Overall, the subsequent effects of artificial intervention on the dilution of $\mathrm{PM}_{10}$ and $\mathrm{PM}_{2.5}$ were significant, which was consistent with the research results from Chen et al. [22].

\section{Effects of MLH on Air Pollution}

\subsection{The Relationship between Daily Average MLH and Air Pollutant Concentrations}

Due to the fact that MLH is an important parameter reflecting the vertical diffusion capacity of atmosphere, it is of great significance to study the relationship between MLH and air pollution for urban pollution potential prediction. The washout and inhibition of rainfall can affect the relationship MLH and air pollution [23]. So rainy days have been excluded from the analysis data in this paper. The correlation coefficient of daily average MLH and air pollutant concentrations from 2017-2019 in the region was calculated as shown in table 4 . From the table, the correlations between 
MLH and the concentrations of $\mathrm{PM}_{2.5}, \mathrm{PM}_{10}, \mathrm{NO}_{2}$ and $\mathrm{CO}$ were all negative. The corresponding coefficients were $-0.71,-0.63,-0.32,-0.43$ and all went through the significance test of 0.01 from the two stations.

Table 3. Correlation coefficients of pollutant concentrations on first and second day after artificial precipitation operations.

\begin{tabular}{|c|c|c|c|c|c|c|c|c|c|c|}
\hline \multicolumn{3}{|l|}{ Correlation } & \multirow{2}{*}{$\mathbf{P M}_{2.5}$} & \multirow{2}{*}{$\mathbf{P M}_{10}$} & \multirow{2}{*}{$\mathrm{SO}_{2}$} & \multirow{2}{*}{$\mathrm{NO}_{2}$} & \multirow{2}{*}{$\mathrm{CO}$} & \multirow{2}{*}{$\mathbf{O}_{3}$} & \multirow{2}{*}{$\mathbf{O}_{3} \_8 \mathrm{~h}$} & \multirow{2}{*}{ AQI } \\
\hline Date & Start time & End time & & & & & & & & \\
\hline $2017 / 11 / 7$ & $13: 23: 00$ & $15: 58: 00$ & 0.48 & 0.27 & 0.13 & 0.85 & 0.53 & 0.97 & 0.75 & 0.29 \\
\hline $2017 / 11 / 8$ & $12: 47: 00$ & $15: 20: 00$ & 0.68 & 0.69 & 0.88 & 0.88 & 0.91 & 0.93 & 0.83 & 0.78 \\
\hline $2017 / 11 / 13$ & $12: 58: 00$ & $16: 06: 00$ & 0.89 & 0.81 & 0.25 & 0.86 & 0.16 & 0.74 & 0.18 & 0.73 \\
\hline $2017 / 11 / 14$ & $12: 33: 00$ & $15: 03: 00$ & 0.50 & 0.53 & 0.90 & 0.62 & 0.72 & 0.73 & 0.41 & 0.56 \\
\hline $2017 / 11 / 18$ & $12: 15: 00$ & 15:00:00 & 0.73 & 0.63 & 0.05 & 0.53 & 0.50 & 0.10 & 0.47 & 0.59 \\
\hline $2018 / 4 / 5$ & 11:08:00 & $13: 10: 00$ & 0.78 & 0.84 & 0.05 & 0.16 & 0.18 & 0.54 & 0.78 & 0.75 \\
\hline $2018 / 4 / 6$ & $9: 26: 00$ & $12: 05: 00$ & - & - & - & - & - & - & - & - \\
\hline $2018 / 4 / 14$ & 9:53:00 & $10: 34: 00$ & 0.50 & 0.41 & 0.41 & 0.38 & 0.50 & 0.20 & 0.61 & 0.50 \\
\hline $2018 / 4 / 15$ & $14: 06: 00$ & $16: 47: 00$ & 0.90 & 0.50 & 0.68 & 0.25 & 0.70 & 0.42 & 0.47 & 0.44 \\
\hline $2018 / 4 / 21$ & $9: 48: 00$ & $11: 55: 00$ & 0.58 & 0.74 & 0.08 & 0.70 & 0.75 & 0.97 & 1.00 & 0.68 \\
\hline $2018 / 4 / 23$ & $14: 48: 00$ & $15: 13: 00$ & 0.18 & 0.10 & 0.28 & 0.44 & 0.32 & 0.37 & 0.46 & 0.10 \\
\hline $2018 / 4 / 27$ & $12: 00: 00$ & $14: 30: 00$ & 0.09 & 0.76 & 0.40 & 0.76 & 0.66 & 0.92 & 0.96 & 0.36 \\
\hline $2018 / 5 / 7$ & $14: 30: 00$ & 15:00:00 & 0.33 & 0.57 & 0.79 & 0.48 & 0.08 & 0.62 & 0.84 & 0.30 \\
\hline $2019 / 3 / 29$ & $9: 15: 00$ & 11:01:00 & 0.53 & 0.59 & 0.46 & 0.90 & 0.44 & 0.67 & 0.79 & 0.54 \\
\hline $2019 / 4 / 11$ & $12: 16: 00$ & $15: 07: 00$ & 0.73 & 0.73 & 0.18 & 0.73 & 0.54 & 0.78 & 0.89 & 0.68 \\
\hline
\end{tabular}

Table 4. Correlations and significance test between MLH and pollutant concentrations.

\begin{tabular}{llllll}
\hline $\mathbf{P M}_{2.5}$ & $\mathbf{P M}_{10}$ & $\mathbf{S O}_{2}$ & $\mathbf{N O}_{2}$ & $\mathbf{C O}$ & $\mathbf{O}_{3}$ \\
\hline$-0.71^{*}$ & $-0.63^{*}$ & 0.23 & -0.32 & $-0.43^{*}$ & $0.51^{*}$ \\
\hline
\end{tabular}

Note: * The correlation coefficient went through the 0.01 significance test.

And on the contrary, the correlations showed a positive way with the concentrations of $\mathrm{SO}_{2}$ and $\mathrm{O}_{3}$. The data certified that MLH has the best correlation with the concentrations of $\mathrm{PM}_{2.5}$ and $\mathrm{PM}_{10}$, which identified that with the increase of $\mathrm{MLH}$, the concentrations of particulate pollutants were diluted.

\subsection{The Relationship between MLH and Air Pollutant Concentrations after Intervention}

The MLH, surface ventilation with the corresponding concentration sequences of $\mathrm{PM}_{2.5}$, $\mathrm{PM}_{10}, \mathrm{SO}_{2}, \mathrm{NO}_{2}, \mathrm{CO}, \mathrm{O}_{3}$ and AQI from each hour artificial interventions for 18 hours in 16 times of artificial intervention operations during 2017-2019 in the region were analyzed and they all went through the significance test of 0.001 as shown in table 5 . From the table, $\mathrm{PM}_{2.5}, \mathrm{PM}_{10}, \mathrm{SO}_{2}, \mathrm{NO}_{2}, \mathrm{CO}$ and $\mathrm{AQI}$ indexed were negatively correlated with MLH and surface ventilation. This certified that with the increases of $\mathrm{MLH}$ and surface ventilation, the concentrations of $\mathrm{PM}_{2.5}, \mathrm{PM}_{10}, \mathrm{SO}_{2}, \mathrm{NO}_{2}$ and $\mathrm{CO}$ decreased and it was helpful for eliminating the above pollutants. And, the concentration sequences of $\mathrm{O}_{3}$ were positively correlated with MLH and surface ventilation, which certified that the turbulence intensified during the artificial intervention and the concentration of $\mathrm{O}_{3}$ increased, which had no effect on $\mathrm{O}_{3}$ removal. Among the pollutants, $\mathrm{PM}_{10}$ had the highest correlation coefficient with MLH and 
surface ventilation, up to -0.35 and -0.44 respectively, which identified that artificial intervention on $\mathrm{PM}_{10}$ removal was clearest.

Table 5. Correlations and significance test of MLH, surface ventilation and pollutant concentrations after artificial precipitation operations.

\begin{tabular}{lllllll}
\hline Correlation coefficients & $\mathbf{P M}_{\mathbf{2 . 5}}$ & $\mathbf{P M}_{\mathbf{1 0}}$ & $\mathbf{S O}_{\mathbf{2}}$ & $\mathbf{N O}_{2}$ & $\mathbf{C O}$ & $\mathbf{O}_{3}$ \\
\hline MLH & -0.18 & -0.35 & -0.20 & -0.09 & -0.12 & 0.30 \\
Surface ventilation & -0.16 & -0.44 & -0.24 & -0.13 & -0.13 & 0.55 \\
\hline
\end{tabular}

\section{Discussions and Conclusions}

(1) There was an obvious daily variarion on MLH. It varied smoothly during deep night and 10:00, increased gradually from 11:00, and reached an obvious peak from 13:00 to 15:00. And in non-haze days, it was generally higher than that in haze days, which was about one time higher on average.

(2) MLH, pollutant concentrations and visibility varied significantly after artificial intervention: The MLH and surface ventilation increased progessively; the visibility increased significantly; the concentrations of $\mathrm{PM}_{2.5}$ and $\mathrm{PM}_{10}$ decreased; the concentrations of coarse mode particles were obviously weakened; the subsequent dilution effect on $\mathrm{PM}_{2.5}$ and $\mathrm{PM}_{10}$ was obvious, especially on $\mathrm{PM}_{10}$.

(3) The daily average concentrations of $\mathrm{PM}_{2.5}$ and $\mathrm{PM}_{10}$ were positively correlated with the daily average MLH in the region and the correlation coefficients are -0.71 and -0.63 respectively. After the artificial intervention, $\mathrm{PM}_{2.5}, \mathrm{PM}_{10}, \mathrm{SO}_{2}, \mathrm{NO}_{2}, \mathrm{CO}$, AQI indexes were negatively correlated with MLH and surface ventilation while positively correlated with $\mathrm{O}_{3}$.

This research showed the increase trend of MLH and surface ventilation after intervention. The more the MLH increases, the better the pollutants diffuse. Many studies like Yang et al. [24] probed into the effects of MLH on air pollution in Urumqi, from which a comparatively similar conclusion of "With the increase of MLH, the vertical diffusion range of pollutants increases and the pollution level near the surface decreases" was obtained. And in this paper, it was found the dilution effects of artificial intervention on $\mathrm{PM}_{2.5}$ and $\mathrm{PM}_{10}$ were obvious, especially on $\mathrm{PM}_{10}$, which was consistent with previous studies. Chen et al. [22] analyzed the effects of artificial precipitation enhancement on air quality the in Chongqing Urban Area and proved that the enhancement purified obviously the air during the winter half-year in Chongqing. Especially, the purifications on $\mathrm{PM}_{10}$ and $\mathrm{SO}_{2}$ were better than that on $\mathrm{NOx}$, and artificial precipitation can increase the number of days reaching the urban air quality standards by 34-62 days on average.

The limited number of operation stations and cases selected for artificial precipitation may result in the boundries of the results. More experiments in different cases will be conducted in future studies.

\section{Acknowledgement}

This paper was supported by Natural Science Foundation of Guangdong ProvinceMajor Basic Research and Cultivation Projects (2015A030308014). 


\section{References}

[1] Li D S, Zhang C C, Xu H B, et al. 2002 Present Situation and Prospect of Weather Modification (Beijing: China Meteorological Press).

[2] Guo X L, Fu D H, Hu Z X, et al. 2013 Progress in cloud physics, precipitation, and weather modification during 2008-2012 Chinese Journal of Atmospheric Sciences 37 (2) 351-363. (in Chinese)

[3] Li H B, Fu Y, Zhang J X, et al. 2018 Precipitation weather characteristics and correlation analysis of an atmospheric pollution process Meteorology Monthly 44 (5) 655-664.

[4] Gao J Q, Lin ZH G, Lin J J, et al. 2014 Feasibility analysis of Pearl River Delta artificial precipitation to reduce haze Guangdong Meteorology 36 (1) 59-62.

[5] Bao X D, Ding J F, Guo X L, et al. 2019 Design idea of weather modification integration intelligent operational system in Henan Meteorological and Environmental Sciences 42 (2) 115-123.

[6] Wang W J, Yao Z, Y Jia S H, et al. 2018 Application research on random forest algorithm in the statistical test of rainfall enhancement effect Meteorological and Environmental Sciences 41 (2) 111117.

[7] Liu Y H, Zhou Y Q, Huang Y M, et al. 2019 Simulation analysis of cloud structure and artificial enhancement precipitation condition of a cold-front rainfall Meteorological and Environmental Sciences 42 (1) 60-72.

[8] Gao J Q, Lin W S, Dong Z H, et al. 2014 Feasibility analysis of Pearl River Delta artificial precipitation to reduce haze Guangdong Meteorology 36 (1) 59-62.

[9] Cao H L and Su J 2014 Variation characteristics of mixed layer thickness and its influence on air pollution in Xi'an Area Shangxi Meteorology (5) 32-35.

[10] Zhou Y and Xiang W G 2018 Characteristics of Sichuan Basin atmospheric mixed layer height and its correlation with AQI Journal of Chengdu University of Information Technology 33 (5) 562-571.

[11] Li M, Tang G Q and Huang J 2015 Relationship between winter atmospheric mixing layer Height and air pollution in Beijing, Tianjin, Hebei Environmental Science 36 (6) 1935-1943.

[12] Liao G L 2005 Calculation method and influence factor of atmospheric mixing layer thickness Journal of National Sun Yat-sen University 26 (4) 66-73.

[13] Yu K A, Chen L, Chen Y L, et al. 2019 Diurnal variation and characteristics of the atmospheric mixed layerheight in haze and nonhaze days in Ningbo Journal of the Meteorological Sciences 39 (2) 187-193.

[14] You H L, Liu W D and Tan J R 2010 Temporal variation characteristics of mean maximum mixed layer thickness in Beijing area Meteorology Monthly 36 (5) 51-55.

[15] Liao Z H, Xu X Q, Xie J L, et al. 2019 Daily maximum mixing height and its effects on air quality in the Pearl River Delta region Journal of Meteorology and Environment 35 (5) 85-92.

[16] Shi B Z, Zheng F C and Cao G L 1997 Comparative analysis of methods for determination of atmospheric mixed layer height Journal of Xi'an University of Architecture and Technology 29 (2) 138141.

[17] Xu D H and Zhu R 1989 Study on the distribution of ventilation and rain washing capacity in China Mainland China Environmental Science 9 (5) 367-374.

[18] Welton E J, Voss K J, Gordon H R, et al. 2000 Ground-based lidar measurements of aerosols during ACE-2: Instrument description, results, and comparisons with other ground-based and airborne measurements Tellus 52B 636-651.

[19] Welton E J, Voss K J, Quinn P K, et al. 2002 Measurements of aerosol vertical profile and optical properties during INDOEX 1999 using micrpulse lidars J. Geophys. Res. 107 8019-8041.

[20] Cohn S A and Angevine W M 2000 Boundary-layer height and entrainment zone thickness measured by lidars and wind profiling radars J. Appl. Meteorol. 39 1233-1247.

[21] He Q S and Mao J T 2005 Vertical Distribution of atmospheric mixing layer and aerosol in Beijing Acta Meteorologica Sinica 63 374-384.

[22] Chen X M and Li K 2010 Influence of artificial precipitation on air quality in Chongqing urban area Journal of Southwest China Normal University: Natural Science 35 (6) 152-156.

[23] Hu L, Cao H L, Zhang W J, et al. 2013 Variation characteristics of ambient air quality in Xi'an and its relationship with meteorological conditions Journal of Meteorology and Environment 29 (6) 150-153.

[24] Yang X H, He Q, Liu T, et al. 2010 A case study of mixing layer thickness and its effect on air pollution in winter in Urumqi Desert and Oasis Meteorology April (4) 18-21. 